\title{
Mini-laparoscopic versus traditional laparoscopic cholecystectomy: A preliminary study
}

\author{
Deniz Atasoy, Afag Aghayeva, Volkan Özben, Onur Bayraktar, İsmail Hamzaoğlu, Bilgi Baca \\ Department of General Surgery, Acıbadem Mehmet Ali Aydınlar University Faculty of Medicine, İstanbul, Turkey
}

\begin{abstract}
Introduction: The use of smaller instruments in laparoscopy has been hypothesized to reduce pain and increase cosmesis. However, although nearly 2 decades have passed since the first mini-laparoscopic cholecystectomy (MLC), it has gained little interest. The aim of this study was to compare the outcomes of MLC with a traditional laparoscopic cholecystectomy (TLC).

Materials and Methods: Patients who underwent MLC between February 6, 2016 and October 26, 2016 were included in this study. As a comparison group, patients who had TLC performed during the same period were also evaluated. The variables studied were demographic details, operating time, blood loss, postoperative pain score, length of hospital stay, and the early ( $<30$ day) complication rate.

Results: A total of 16 MLCs and 75 TLCs were performed. In the MLC group, there were 6 (37.5\%) men and 10 (62.5\%) women with a mean age of $40.94 \pm 12.3$ years. In the comparison group, there were $35(46.7 \%)$ men and $40(53.3 \%)$ women with a mean age of $46.36 \pm 14.86$ years. No patients were converted to open surgery. The average operating time was $47.06 \pm 15.15$ minutes in the MLC group and $70.53 \pm 40.04$ minutes in the TLC group $(p=0.021)$. The average blood loss was $1.88 \pm 1.86 \mathrm{~mL}$ and $10.00 \pm 22.19 \mathrm{~mL}$ in MLC and TLC groups, respectively $(p=0.005)$. The mean Visual Analogue Scale (VAS) score was $30.00 \pm 19.66$ and $32.93 \pm 21.59$, respectively, and the length of hospital stay was $1.19 \pm 0.40$ days and $1.47 \pm 1.09$ days in MLC and TLC groups, respectively ( $p=0.689$ and $p=0.486$, correspondingly). There were $2(2.2 \%)$ early $(<30$ days) postoperative complications. The mortality was nil.

Conclusion: According to the results of this preliminary study, MLC was a safe and feasible variant of laparoscopic cholecystectomy. With respect to the length of hospital stay and complication rate, both procedures were equal. Additionally, a decrease in the incisional hernia rate of the "mini" ports could be hypothesized. Further studies with a larger cohort are needed.

Keywords: Cholecystectomy; cholecystitis; cholelithiasis; laparoscopy; minilaparoscopy.
\end{abstract}

\section{Introduction}

Laparoscopic cholecystectomy is considered as the gold standard for the treatment of cholelithiasis. ${ }^{[1-3]}$ Since introduction of the laparoscopy to the surgical practice, minimally invasive surgery is evolving. ${ }^{[4]}$
Not only the quality and ergonomics but also the diameter of the instruments is improving. To reduce the invasiveness in traditional laparoscopic cholecystectomy (TLC), reduced number and decreased-diameter ports have 
been described including single port, ${ }^{[5]}$ two ports, ${ }^{[6]}$ three ports ${ }^{[7]}$ and four ports mini-laparoscopic cholecystectomy (MLC) ${ }^{[1,4,8-12]}$ techniques.

Studies regarding the cholecystectomy procedure with the use of thinner laparoscopic instruments have been published in the past. ${ }^{[4,11-15]}$ However, so-called 'mini' approach gained little interest most probably due to decreased durability of the reduced size instruments, poorer optical resolution and the smaller jaws of the instrument tips. ${ }^{[1,4]}$

The use of thinner instruments has been hypothesized to reduce pain and increase cosmesis. ${ }^{[9]}$ However, any additional benefits of the "mini" laparoscopy need investigation.

The benefits of TLC in terms of shorter length of hospital stay, less pain, improved cosmesis and faster recovery compared to open surgery were demonstrated previously. $[4,16,17]$ If minimal invasiveness is the reason of these benefits compared to open cholecystectomy, then it could be hypothesized that further miniaturized instruments would cause less tissue trauma and further improved outcomes.

The aim of this pilot study was to compare the outcomes of MLC with TLC.

\section{Materials and Methods}

After approval of the institutional review board (No: 2016$13 / 4$ ), our prospectively maintained registry of patients who underwent MLC or TLC operations between February 6 and October 26, 2016 was reviewed retrospectively.

Patients were explained about the details of the procedures and informed consent was signed by all patients.

The parameters compared were demographic variables, operating time, blood loss, postoperative pain score, length of hospital stay, and early ( $<30$ day) complication rate. Complications were graded according to the ClavienDindo classification. ${ }^{[18]}$

Postoperative pain was scored according to visual analogue scale (VAS) (0, no pain to 10 , the worst pain) assessed on postoperative day one.

\section{Surgical Technique}

\section{Traditional Laparoscopy}

Patients were placed in a supine, reverse Trendelenburg position and slightly tilted to the left side with left arm placed to the patient's side. After a 12-mm Hg capnoperi- toneum was established with a Veress needle introduced through an umbilical incision, one umbilical 10-mm, one epigastric and two right upper quadrants (anterior axillary line and midclavicular line) 5-mm trocars were introduced to the abdomen (cumulative port size 25$\mathrm{mm}$ ). Following the retraction of gallbladder fundus, the Calot's triangle was dissected and cystic artery and cystic duct were exposed. The duct and artery were cut between Weck $^{\circledR}$ Hem-o-lok ${ }^{\circledR}$ clips, separately. Then, the gallbladder is freed from its liver bed. Finally, the specimen is taken outside the abdominal cavity within a retrieval bag through the umbilical port site. A 5-mm $30^{\circ}$ laparoscope was placed through the epigastric port to facilitate specimen retrieval. Only the fascial edges of the umbilical port were closed with 2-0 Vicryl suture. Suturing of the skin incision ended the operation.

\section{Mini-Laparoscopy}

The TLC approach was modified as follows. Two mini-laparoscopic $(2.4 \mathrm{~mm})$ right upper quadrant instruments (MiniGrip Alligator grasper and MiniLap grasper, Teleflex Inc.), one $5 \mathrm{~mm}$ epigastric port, and one $10 \mathrm{~mm}$ umbilical port were used (cumulative port size $19.8 \mathrm{~mm}$ ). Operation steps followed were the same as described for TLC. Skin incisions of 'mini' instruments were approximated with Steri-strips (3M, St Paul, Minn) without suturing.

\section{Statistical Analysis}

Fischer exact test and chi-square test were used to compare categorical variables and the t-test was used for continuous variables to determine statistical significance, with significance set at $\mathrm{p}<0.05$. Mann-Whitney $U$ test was used to compare pain scores.

\section{Results}

A total of 91 patients were included to this study. Patients were grouped into two regarding the type of instruments used during laparoscopic cholecystectomy, MLC ( $n=16)$ arm and TLC ( $\mathrm{n}=75)$ arm.

Demographics and perioperative outcomes of the patients are listed in Table 1. Mean age was $40.94 \pm 12.3$ and $46.36 \pm 14.86$ for MLC and TLC patients, respectively $(\mathrm{p}=0.203)$.

Groups were comparable with respect to sex, age, ASA, and etiology of gallbladder disease. The operating time was significantly shorter in the MLC group (47.06 \pm 15.15 
Table 1. Comparison of patient characteristics, operative and postoperative outcomes, and pathologic results between mini-laparoscopic and traditional laparoscopic cholecystectomy groups

\begin{tabular}{|c|c|c|c|}
\hline & $\begin{array}{l}\text { Mini-laparoscopic } \\
\text { cholecystectomy } \\
\quad(n=16)\end{array}$ & $\begin{array}{c}\text { Traditional laparoscopic } \\
\text { cholecystectomy } \\
(n=75)\end{array}$ & $p$ value \\
\hline Gender, F, n (\%) & $10(62.5)$ & $40(53.3)$ & 0.503 \\
\hline Age (year), mean $\pm S D$ & $40.94 \pm 12.3$ & $46.36 \pm 14.86$ & 0.203 \\
\hline $\mathrm{BMI}\left(\mathrm{kg} / \mathrm{m}^{2}\right)$, mean $\pm \mathrm{SD}$ & $25.94 \pm 3.25$ & $28.94 \pm 4.82$ & 0.010 \\
\hline $\operatorname{ASA}(1-2), n$ & $1.13 \pm 0.34$ & $1.44 \pm 0.58$ & 0.036 \\
\hline Etiology, n (\%) & & & 0.581 \\
\hline Stone & $13(81.3)$ & $66(88.0)$ & \\
\hline Polyp & $3(18.8)$ & $7(9.3)$ & \\
\hline Sludge & 0 & $2(2.7)$ & \\
\hline Admission, $\mathrm{n}(\%)$ & & & 0.817 \\
\hline Elective & $13(81.3)$ & $59(78.7)$ & \\
\hline Emergency & $3(18.8)$ & $16(21.3)$ & \\
\hline Previous surgery & & & 0.208 \\
\hline Yes & $8(50.0)$ & $25(33.3)$ & \\
\hline No & $8(50.0)$ & $50(66.7)$ & \\
\hline Operative time (min), mean $\pm S D$ & $47.06 \pm 15.15$ & $70.53 \pm 40.04$ & 0.021 \\
\hline Blood loss (mL), mean $\pm S D$ & $1.88 \pm 1.86$ & $10.00 \pm 22.19$ & 0.005 \\
\hline latrogenic gallbladder perforation, Yes, n (\%) & $4(25.0)$ & $22(29.3)$ & 0.728 \\
\hline Local anesthesia at trocar sites, Yes, n (\%) & $9(56.3)$ & $37(49.3)$ & 0.615 \\
\hline Enlargement of umbilical trocar site & & & 0.090 \\
\hline Yes & $3(18.8)$ & $31(41.3)$ & \\
\hline No & $13(81.3)$ & $44(58.7)$ & \\
\hline VAS score & $30.00 \pm 19.66$ & $32.93 \pm 21.59$ & 0.689 \\
\hline Time to first flatus & $1.13 \pm 0.64$ & $1.30 \pm 0.57$ & 0.356 \\
\hline Time to first defecation & $1.73 \pm 0.46$ & $1.89 \pm 0.53$ & 0.323 \\
\hline Length of stay, day & $1.19 \pm 0.40$ & $1.47 \pm 1.09$ & 0.486 \\
\hline Early (<30 day) complications & & & 1 \\
\hline No & 16 & $73(97.3)$ & \\
\hline Yes & 0 & $2(2.7)$ & \\
\hline
\end{tabular}

Continuous variables are described as mean $\pm S D$, categorical variables are described as $\mathrm{n}(\%)$. Statistical significance is emphasized in bold. BMI: Body mass index; ASA: American Society of Anesthesiologists; VAS: Visual analog scale.

*Categorical variables were compared using the Pearson chi-square test or Fisher's exact test, and continuous variables were compared with the two-tailed Student's t test. When parametric test conditions could not be provided Mann-Whitney $U$ test was used as appropriate.

vs $70.53 \pm 40.04 \mathrm{~min}, \mathrm{p}=0.021)$. No conversions to open occurred. There were no differences in postoperative pain and complications ( $\mathrm{p}=0.689$ vs. $\mathrm{p}=1$, respectively). In the TLC group two patients developed grade III complications. One developed choledocholithiasis on postoperative day one and after successful removal of the stone with endoscopic retrograde cholangiopancreatography (ERCP) the course was uneventful. The other patients developed choledocholithiasis and acute pancreatitis on the sixth postoperative day and was treated conservatively. The stone in the ampulla had fallen by itself without a need for ERCP.

The length of stay did not differ between the groups $(p=0.486)$. There was no mortality in either of the groups.

\section{Discussion}

According to the results of this pilot study, MLC seems to be a feasible and effective technique. However, further technological improvements are needed. ${ }^{[10]}$ 
As a general definition, laparoscopic cholecystectomy technique with less than $5 \mathrm{~mm}$ instruments is named minilaparoscopic cholecystectomy. ${ }^{[19]}$ In the current study, we used two 'mini' laparoscopic instruments. Besides, a conventional umbilical trocar of $10 \mathrm{~mm}$ for specimen extraction and visualization was also utilized.

Superior cosmetic outcomes in favor of MLC are reported in the literature. ${ }^{[1,8]}$ In the current study we didn't compare the cosmetic outcomes, due to the difficulty in observer and patient perception complicating the assessment. The cumulative port size in our technique was $19.8 \mathrm{~mm}$ compared to $25 \mathrm{~mm}$ in the traditional approach. This comprised nearly $21 \%$ (5.2 $\mathrm{mm}$ ) decrease in the total incision length. Up to $50 \%$ decrease is reported by some researchers ${ }^{[1,4]} \mathrm{A}$ further decrease could be achieved with a $2 \mathrm{~mm}$ fiberoptic video-laparoscope inserted through the epigastric port site. Reardon et al. ${ }^{[4]}$ reported that, the optical resolution was a limiting factor and was the primary reason for conversion. The authors further stated that, application of clips through the umbilical port instead of the epigastric port and visualization through the epigastric port was disorienting. Therefore, they didn't use the quartz fiber scope. Instead, they continued to use the standard rod and lens scopes through the umbilical port.

In their prospective randomized study, Alponat et al. ${ }^{[1]}$ compared 17 mini-site cholecystectomies with 22 conventional laparoscopic cholecystectomies. The authors utilized one $10 \mathrm{~mm}$ and three $2 \mathrm{~mm}$ ports (cumulative port size $16 \mathrm{~mm}$ ). The groups were compared in terms of tissue trauma, pulmonary response, postoperative pain, analgesic requirement and cosmetic results. They observed that, only the cosmetic results were superior to conventional laparoscopic cholecystectomy. They concluded that, mini-site cholecystectomy could be an alternative to patients looking for better cosmetic results.

Although the BMI of the MLC group in this study was observed to be lower than TLC group, it was reported that the obesity didn't cause difficulty for this procedure. ${ }^{[1]}$ Lower BMI and ASA of the MLC group in our study could be attributed to a selection bias since the surgeons were in the learning period for this procedure. Similarly, despite the learning period, statistically significantly less blood loss and shorter operating times in the MLC group could also be attributed to the highly selected patient group and small sample size.
Some studies ${ }^{[1,8,10]}$ reported lower postoperative pain after MLC versus TLC, while in this study we couldn't show any difference.

In a meta-analysis, Sajid et al. ${ }^{[20]}$ investigated the clinical trials on needlescopic versus TLC. Only six randomized trials consisting of 317 patients were eligible. They observed that needlescopy was associated with longer operating time and higher conversion rate compared to TLC. Complication rate and length of hospital stay was not statistically different. Needlescopy was found to be better regarding postoperative pain and cosmetic outcomes. Similarly, in the current study, the length of hospital stays and complication rate did not differ between the groups.

An additional potential advantage of the 'mini' laparoscopic technique could be its hypothetical decrease in trocar-site incisional hernia. Comparative studies are needed before any definite declarations.

There were some observations regarding the use of the 'mini' instruments. First, the instruments were relatively weak compared to conventional ones. They could be easily damaged under forced use. Second, jaws and shafts were also thinner that resulted with weaker manipulation of the gallbladder. Therefore, their use in obese patients, in the presence of dense adhesions, in inflamed and thick gallbladders could be inadequate. ${ }^{[10]}$ In addition, unshielded instruments could cause trouble during hemostasis. ${ }^{[1,4]}$ Besides, it was reported that, the vision of the needlescopic scopes was inferior to $10 \mathrm{~mm}$ scopes ${ }^{[1,10]}$ and utilization of the $2 \mathrm{~mm}$ scope through the epigastric port could be disorienting. These shortcomings might prevent the standardization of this technique as a first choice in the treatment of gallstone disease. Further technological improvements are needed.

In conclusion, MLC can be performed safely using $10 \mathrm{~mm}$ umbilical, $5 \mathrm{~mm}$ epigastric, and two $2.4 \mathrm{~mm}$ right upper quadrant ports. A further decrease in some of the trocar sizes could be important in patients to whom a 'small' scar is a 'big' problem. Better 'mini' optics and clip appliers would further decrease the epigastric port incision enabling a further less minimal invasive cholecystectomy. Further studies are needed for concluding statements.

\section{Disclosures}

Ethichs Committee Approval: The study was approved by the Local Ethics Committee. 
Peer-review: Externally peer-reviewed.

Conflict of Interest: None declared.

\section{References}

1. Alponat $A$, Cubukçu $A$, Gönüllü N, Cantürk Z, Ozbay O. Is minisite cholecystectomy less traumatic? Prospective randomized study comparing minisite and conventional laparoscopic cholecystectomies. World J Surg 2002;26:1437-40.

2. Gallstones and laparoscopic cholecystectomy. NIH Consens Statement 1992;10:1-28.

3. Buia A, Stockhausen F, Hanisch E. Laparoscopic surgery: A qualified systematic review. World J Methodol 2015;5:23854. [CrossRef]

4. Reardon PR, Kamelgard JI, Applebaum B, Rossman L, Brunicardi FC. Feasibility of laparoscopic cholecystectomy with miniaturized instrumentation in 50 consecutive cases. World J Surg 1999;23:128-31. [CrossRef]

5. Pan $M X$, Jiang ZS, Cheng $Y, X u$ XP, Zhang Z, Qin JS, et al. Single-incision vs three-port laparoscopic cholecystectomy: prospective randomized study. World J Gastroenterol 2013;19:394-8. [CrossRef]

6. Poon CM, Chan KW, Lee DW, Chan KC, Ko CW, Cheung HY, et al. Two-port versus four-port laparoscopic cholecystectomy. Surg Endosc 2003;17:1624-7. [CrossRef]

7. Cerci C, Tarhan OR, Barut I, Bülbül M. Three-port versus fourport laparoscopic cholecystectomy. Hepatogastroenterology 2007;54:15-6.

8. Sarli L, Costi R, Sansebastiano G. Mini-laparoscopic cholecystectomy vs laparoscopic cholecystectomy. Surg Endosc 2001;15:614-8. [CrossRef]

9. Novitsky YW, Kercher KW, Czerniach DR, Kaban GK, Khera S, Gallagher-Dorval KA, et al. Advantages of mini-laparoscopic vs conventional laparoscopic cholecystectomy: results of a prospective randomized trial. Arch Surg 2005;140:1178-83.

10. Huang MT, Wang W, Wei PL, Chen RJ, Lee WJ. Minilaparoscopic and laparoscopic cholecystectomy: a comparative study. Arch Surg 2003;138:1017-23. [CrossRef]

11. Bisgaard $T$, Klarskov B, Trap R, Kehlet H, Rosenberg J. Microlaparoscopic vs conventional laparoscopic cholecystectomy: a prospective randomized double-blind trial. Surg Endosc 2002;16:458-64. [CrossRef]

12. Bisgaard T, Klarskov B, Trap R, Kehlet H, Rosenberg J. Pain after microlaparoscopic cholecystectomy. A randomized double-blind controlled study. Surg Endosc 2000;14:340-4.

13. Yuan RH, Lee WJ, Yu SC. Mini-laparoscopic cholecystectomy: a cosmetically better, almost scarless procedure. J Laparoendosc Adv Surg Tech A 1997;7:205-11. [CrossRef]

14. Yu SC, Yuan RH, Chen SC, Lee WJ. Combined use of minilaparoscope and conventional laparoscope in laparoscopic cholecystectomy: preservation of minimal invasiveness. J Laparoendosc Adv Surg Tech A 1999;9:57-62. [CrossRef]

15. Schwenk W, Neudecker J, Mall J, Böhm B, Müller JM. Prospective randomized blinded trial of pulmonary function, pain, and cosmetic results after laparoscopic vs. microlaparoscopic cholecystectomy. Surg Endosc 2000;14:345-8.

16. Newman RM, Umer A, Bozzuto BJ, Dilungo JL, Ellner S. Surgical Value of Elective Minimally Invasive Gallbladder Removal: A Cost Analysis of Traditional 4-Port vs Single-Incision and Robotically Assisted Cholecystectomy. J Am Coll Surg 2016;222:303-8. [CrossRef]

17. Stiff G, Rhodes M, Kelly A, Telford K, Armstrong CP, Rees BI. Long-term pain: less common after laparoscopic than open cholecystectomy. Br J Surg 1994;81:1368-70. [CrossRef]

18. Dindo D, Demartines N, Clavien PA. Classification of surgical complications: a new proposal with evaluation in a cohort of 6336 patients and results of a survey. Ann Surg 2004;240:205-13. [CrossRef]

19. Gaillard $M$, Tranchart $H$, Lainas $P$, Dagher I. New minimally invasive approaches for cholecystectomy: Review of literature. World J Gastrointest Surg 2015;7:243-8. [CrossRef]

20. Sajid MS, Khan MA, Ray K, Cheek E, Baig MK. Needlescopic versus laparoscopic cholecystectomy: a meta-analysis. ANZ J Surg 2009;79:437-42. [CrossRef] 